\title{
Optimal placement of wind turbine in a radial distribution network using PSO method
}

Yahiaoui Merzoug, Bouanane Abdelkrim, Boumediene Larbi

L.G.E Laboratory, Departement of Electrical Engineering, Dr. Moulay Taher University of Saida, Algeria

\begin{tabular}{|c|c|}
\hline Article Info & ABSTRACT \\
\hline Article history: & The aim of this article is to apply the Particle Swarm Optimization (PSO) \\
\hline Received Aug 23, 2019 & $\begin{array}{l}\text { method to find the best location for the wind turbine in the radial distribution } \\
\text { network. The optimal location is found using the loss sensitivity factor. By }\end{array}$ \\
\hline Revised Nov 9, 2019 & respecting the constraints of the active power transmitted in the branches and \\
\hline Accepted Jan 22, 2020 & $\begin{array}{l}\text { the limits of the voltages modules for all the nodes. The validity of this } \\
\text { method is tested on a } 33 \text {-IEEE test network and the results obtained are }\end{array}$ \\
\hline Keywords: & \\
\hline
\end{tabular}

Particle swarm optimization

Radial distribution system

Distributed generation

This is an open access article under the CC BY-SA license.

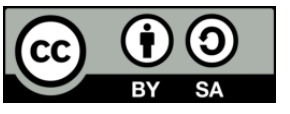

\section{Corresponding Author:}

Yahiaoui Merzoug,

L.G.E Laboratory, Departement of Electrical Engineering,

Dr. Moulay Taher University of Saida, Algeria,BP 138 En-Nasr, (20000 Saida), Algeria.

Email: myahiaoui2001@yahoo.fr

\section{INTRODUCTION}

Electric power, worldwide, has become a consumer good for both everyday life and the economy of the countries, and the smallest problems of electrical origin have a great influence on the continuity of economic activities. Therefore, the possession of reliable and economical electricity networks operating properly and ensuring a continuity of service and a good quality of energy has become essential in order to contribute positively to the development of our modern societies.

The distribution network must evolve towards a flexible and intelligent network that best integrates local and / or renewable energies. The opening up of the electricity market and the growing environmental concerns linked to global climate change are leading to significant changes, particularly in distribution networks, with the massive influx of decentralized products. This evolution can be envisaged by developing intelligent systems, capable of minimizing the impacts generated by the insertion of decentralized productions and / or by the search for new architectures. These two solutions should allow the increase of the decentralized production rate in the distribution network under the best economic and security conditions.

The distribution network was not originally designed to house production units, but to provide unidirectional electricity from the distribution network to medium and low voltage consumers. The use of Distributed intelligent systems alone will not be enough to eliminate all the problems that the distribution network will face in case of significant penetration of decentralized productions [1].

Distribution networks are branched radial topology networks and have several load nodes. The problem that arises is how to choose the best location of GED (decentralized energy generator) in a distribution network. This problem is the subject of research thematic of this article, for this we have used the software for calculating the power flow and calculate some parameters to determine the best node of GED connection. 
Several methods have been used to choose the optimal location of the wind turbine in the distribution network in order to reduce the active losses. [2], Try to provide a comprehensive approach to solve the problem of placement and determining the capacity of wind units in the network. [3], presents a voltage sensitivity analysis with respect to the real power injected with renewable energies to determine the optimal integration of distributed generation (DG) in distribution systems (DS).

In this article, a technique used is based on the particle swarm optimization method (PSO) to determine an optimal allocation of wind-based distributed generators in order to reduce the real power loss of the distribution system. The developed method is implemented on the IEEE 33 bus test system. The work plan for this article has been organized as follows: The basic mathematical model of radial distribution systems is presented in the Section 2. Wind generation system modeling is given in Section 3. In section 4 Loss sensitivity factor and PSO method is used for optimal allocation of wind. Results and Discussion explained in section5. Finally, concludes this paper and proposes perspectives for continuation work.

\section{Mathematical model}

\subsection{Power flow formulation}

The goal of this article is to find the optimal location of the wind turbine in the network in order to minimize active losses. The technique proposed for calculating the power flow in the radial distribution network is based mainly on knowledge of the topology or architecture of the network. The single-line diagram is shown in Figure 1. The power flow equations are given by [4-6].

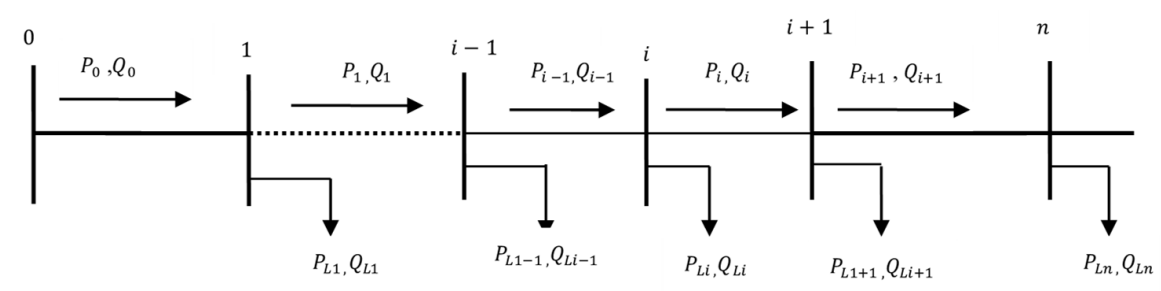

Figure 1. Single line diagram of radial feeder

$$
\begin{aligned}
& P_{i+1}=P_{i}-P_{L i+1}-R_{i, i+1} \cdot \frac{P_{i}^{2}+Q_{i}^{2}}{\left|V_{i}\right|^{2}} \\
& Q_{i+1}=Q_{i}-Q_{L i+1}-X_{i, i+1} \cdot \frac{P_{i}^{2}+Q_{i}^{2}}{\left|V_{i}\right|^{2}} \\
& \left|V_{i+1}\right|^{2}=\left|V_{i}\right|^{2}-2\left(R_{i, i+1} \cdot P_{i}+X_{i, i+1} \cdot Q_{i}\right) \cdot \frac{P_{i}^{2}+Q_{i}^{2}}{\left|V_{i}\right|^{2}}
\end{aligned}
$$

Where, $P_{i}$ and $Q_{i}$ are the real and reactive power flowing out of bus $i ; P_{L i+1}$ and $Q_{L i+1}$ are the real and reactive load powers at bus $i+1$.line section between buses $i$ and $i+1$ has resistance $R_{i, i+1}$ and reactance $X_{i, i+1}$. voltage magnitude of bus $i$ is $\left|V_{i}\right|$.for convergence of power flow , the power balance (1)and (2) must be satisfied in addition, magnitudes of sending and receiving end bus voltages must satisfy (3). The well known generalized formulas for real and reactive power loss in the line section between buses $i$ and $i+1$ are calculated by using the following equations.

$$
\begin{aligned}
& P_{\operatorname{Loss}(i, i+1)}=R_{i, i+1} \cdot \frac{P_{i}^{2}+Q_{i}^{2}}{\left|V_{i}\right|^{2}} \\
& Q_{\text {Loss }(i, i+1)}=X_{i, i+1} \cdot \frac{P_{i}^{2}+Q_{i}^{2}}{\left|V_{i}\right|^{2}}
\end{aligned}
$$

The total active and reactive losses in the distribution network can be easily found by adding all the power losses in all branches and they are expressed as follows.

$$
\begin{aligned}
& P_{\text {tloss }}=\sum_{i=1}^{n b r} P_{\text {Loss }}(i, i+1) \\
& Q_{\text {tloss }}=\sum_{i=1}^{n b r} Q_{\text {Loss }}(i, i+1)
\end{aligned}
$$

Optimal placement of wind turbine in a radial distribution network using PSO method (Yahiaoui Merzoug) 
Where, $P_{\text {tloss }}$ is the total real power loss and $Q_{\text {tloss }}$ is the loss incurred due to reactive power throughout the network. In this study we consider wind supplying real power with unity power factor.

\subsection{Electrical grid operating constraints}

To ensure the stability of the network and the safety of equipment, voltage must be maintained within limits set by the rules of operation of the power grids.

$$
V \min \leq V i \leq V \max
$$

Where Vmin and Vmax are the minimum and maximum values of bus voltage amplitudes, respectively. And the power transited in a line must not, under any circumstances, exceed the maximum limit.

$$
S_{i j}<S_{i j}^{\max }
$$

With

$$
S_{i j}=\left(P_{i j}^{2}+Q_{i j}^{2}\right)^{1 / 2}
$$

Where

$S_{i j}$ : Apparent power transmitted in line $i-j$.

And

$S_{i j}^{\max }$ : Maximum apparent power transited in line $i-j$.

\section{WIND GENERATION SYSTEM MODELLING}

The power generated by the wind turbine depends on their type and location, as well as the wind speed [7-12]. The electrical output power of a wind turbine is determined by using (11).

With $V_{\text {cin }}, V_{\text {cout }}, V_{N}$ are different speeds corresponding to the wind turbine and $P_{\text {rated }}$ is rated out pout power of wind turbine and it can be determined from (12).

$$
\begin{gathered}
P_{W}=\left\{\begin{array}{c}
0 V_{w}<V_{\text {cin }} \text { or } V_{w}>V_{\text {out }} \\
P_{\text {rated }} \frac{V_{w}-V_{\text {cin }}}{V_{N}-V_{\text {cin }}} V_{\text {cin }} \leq V_{w} \leq V_{N} \\
P_{\text {rated }} V_{N} \leq V_{w} \leq V_{\text {cout }}
\end{array}\right. \\
P_{\text {rated }}=0.5 \rho A V^{3} C_{p}
\end{gathered}
$$

\section{LOSS SENSITIVITY FACTOR}

The Active power losses in electrical networks are given by (12).

$$
P_{L}=\sum_{i=1}^{N} \sum_{j=1}^{N}\left[\alpha_{i j}\left(P_{i} P_{j}+Q_{i} Q_{j}\right)+\beta_{i j}\left(Q_{i} P_{j}+P_{i} Q_{j}\right)\right]
$$

Where,

$$
\begin{aligned}
& \alpha_{i j}=\frac{r_{i j}}{V_{i} V_{j}} \cos \left(\delta_{i}-\delta_{j}\right) \\
& \beta i j=\frac{r_{i j}}{V_{i} V_{j}} \sin \left(\delta_{i}-\delta_{j}\right)
\end{aligned}
$$

And

$$
\begin{aligned}
& Z_{i j}=r_{i j}+X_{i j} \text { Are the } i j^{t h} \text { of }\left[Z_{b u s}\right] \text { matrix } \\
& P_{i}=P_{G i}-P_{D i} \text { And } Q_{i}=Q_{G i}-Q_{D i}
\end{aligned}
$$

$P_{G i} \& Q_{G i}:$ Active and reactive power of the generator.

$P_{D i} \& Q_{D i}:$ Active and reactive load power

The sensitivity factor of real power loss with respect to real power injection from the DG is given by

Int J Pow Elec \& Dri Syst, Vol. 11, No. 2, June 2020 : 1074 - 1081 


$$
\alpha_{i}=\frac{\partial P_{L}}{\partial P_{i}}=2 \alpha_{i i} P_{i}+2 \sum_{\substack{j=1 \\ j \neq i}}^{N}\left(\alpha_{i j} P_{j}-\beta_{i j} Q_{j}\right)
$$

The sensitivity factor is calculated for each node using the values obtained from the calculation of the basic flow. The node with the lowest loss sensitivity factor will be the best node for DG placement [13-15].

\section{PARTICLE SWARM OPTIMIZATION}

\subsection{Introduction}

The PSO algorithm is initialized by a population of random potential solutions, interpreted as particles moving in the research space. Each particle is attracted to its best position discovered in the past as well as to the best position discovered by the particles of its vicinity (or of the whole swarm, in the global version of the algorithm). The PSO algorithm includes several adjustment parameters which act on the exploration-exploitation compromise [16-22]. Exploration is the ability to test different regions of space in search of good candidate solutions. Exploitation is the ability to focus research around promising solutions in order to get as close to the optimum as possible. The choice of parameters remains largely empirical. A complete analysis of the algorithm was made by Kennedy

In general, a PSO algorithm has three main steps:

- $\quad$ First step: consists in authorizing all the particles arbitrarily distributed across the search space.

- Second step: consists in evaluating the fitness value of the particles in order to determine the best position of each particle and to reveal the particle which has the best overall fitness value in the current swarm.

- Third step: updates the speed of the particles which are then used as information to change the position of all the particles.

In PSO, two different definitions are used: the individual best and the global best. As a particle moves through the search space, it compares its fitness value at the current position to the best fitness value it has ever attained previously. Adjustment of the position and speed of each particle is calculated using the current position $x_{i}$, the best particle position so far Pbest and the best overall particle position in the populationGbest. Velocity of each particle in the next generation can be calculated as:

$$
V_{i}^{k+1}=w V_{i}^{k}+c_{1} r_{1}\left(\text { Pbest }-x_{i}^{k}\right)+c_{2} r_{2}\left(\text { Gbest }-x_{i}^{k}\right)
$$

With $r_{1}$ and $r_{2}$ are two numbers between 0 and 1 while $c_{1}$ and $c_{2}$ are positive constants, respectively. Inertia weight $\mathrm{w}$ is is formulated by the following expression:

$$
w=w_{\max }-\frac{w_{\max }-w_{\min }}{\text { iter }_{\max }} \text { iter }
$$

Where $w_{\max }$ and $w_{\min }$ are maximum and minimum of inertia weight, iter $r_{\max }$ and iter are maximum iteration number and current iteration, respectively.

\subsection{PSO Procedure}

The calculation procedure for the PSO calculation algorithm is as follows.

Step 1: Introduce data for all nodes and branches as well as the limits of nodal voltages.

Step 2: Calculating the power flow in the distribution network and determining total active losses.

Step 3: generate an initial population of particles with random positions and velocity. Set the iteration index $t=0$.

Step 4: For each particle, update the bus data (for wind turbine) based on its locations and setting values, if all nodal voltages are within the permissible limits, estimate the total loss.

Step 5: Compare the fitness value of each particle with the personal best, Pbest. If the fitness value is lower than Pbest, set this value as the current Pbest, and record the particle position corresponding to this Pbest value.

Step 6: Select the minimum value of Pbest from all particles to be the current global best, Gbest, and record the particle position corresponding to this Gbest value.

Step 7: Update the velocity and position of particle.

Optimal placement of wind turbine in a radial distribution network using PSO method (Yahiaoui Merzoug) 
Step 8: If the maximum number of iterations is reached, the particle associated with the current Gbest is the optimal solution and then go to Step 9. Otherwise, set $t=t+1$ and return to Step 4.

Step 9: Displayed the best position for each particle.

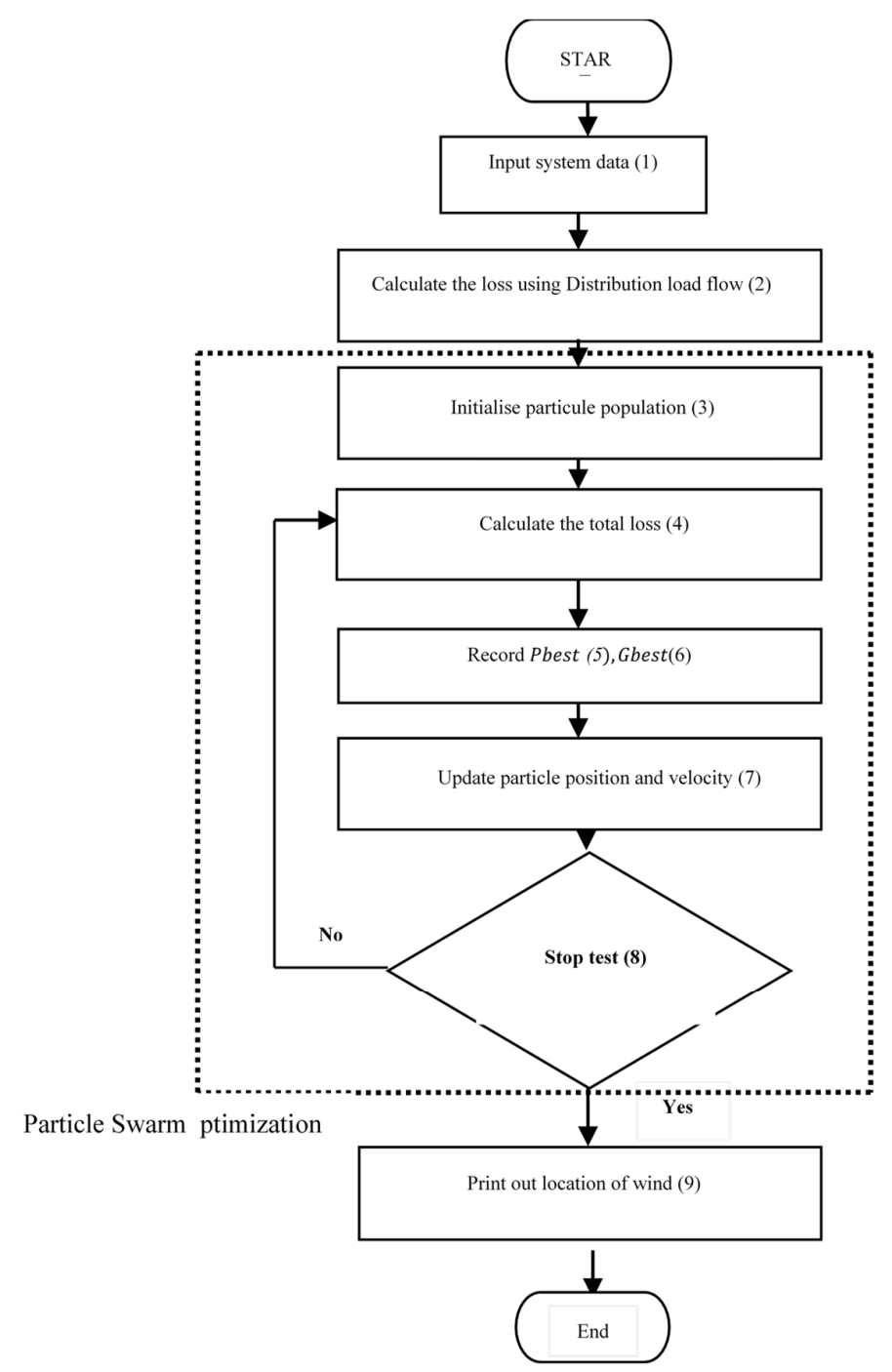

Figure 2: PSO-Optimization Wind computational procedure

\section{RESULTS AND SIMULATIONS}

Optimization of the location of the wind is done by the PSO algorithm, always programmed under MATLAB and tested on the IEEE33-bus distribution network system containing 33 buses and 32 branches as shown in Figure 3. The bus and line data are taken from [23-24]. The real and reactive power loads and voltage of radial distribution system are $3.72 \mathrm{MW}, 2.3 \mathrm{Mvar}$ and $12.66 \mathrm{KV}$ respectively. This program searches for the best wind turbine location on the network to minimize total active losses. 


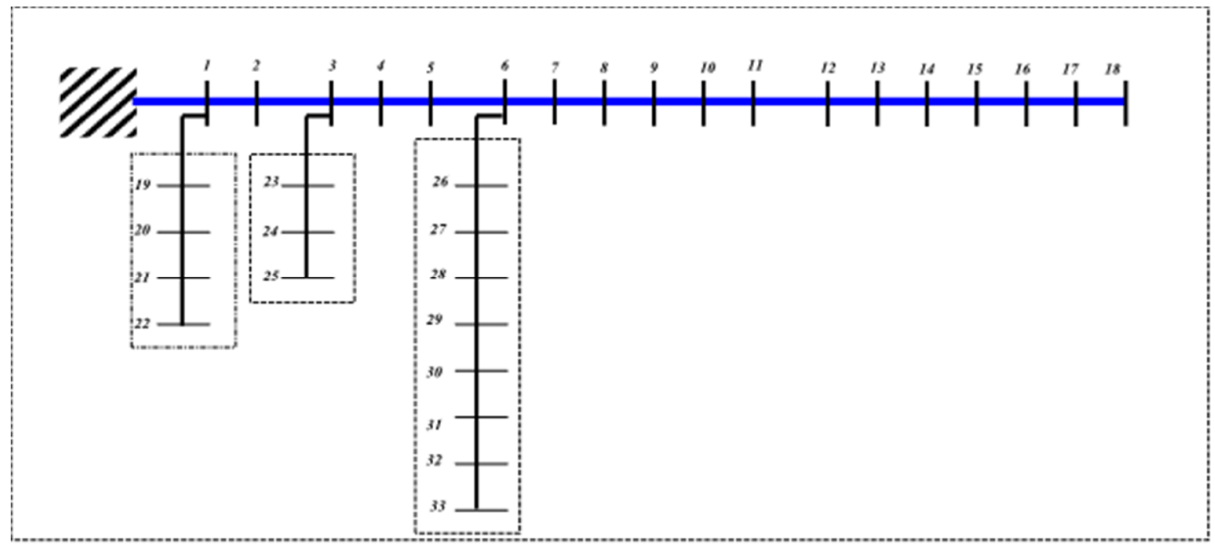

Figure 3. Single line diagram of 33 Bus electric distribution systems.

Voltage sensitivity index was calculated at all nodes. Bus 18 was found to have the least VSI. Hence Wind Turbine was placed at this bus. The active power losses before the placement (basic calculation) of the distributed generator (wind) is 208,492 KW and the minimum voltage is $0.91075 \mathrm{pu}$ at node level number 18. The first step in determining the wind power injected into the grid using the (11), with an average annual wind speed considered to be $6.02 \mathrm{~m} / \mathrm{s}$ to determine the optimal location. [25].

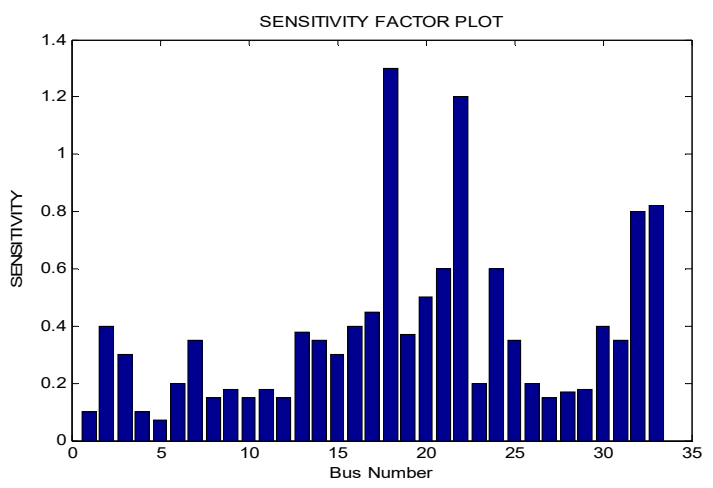

Figure 4. Loss Sensitivity at all nodes

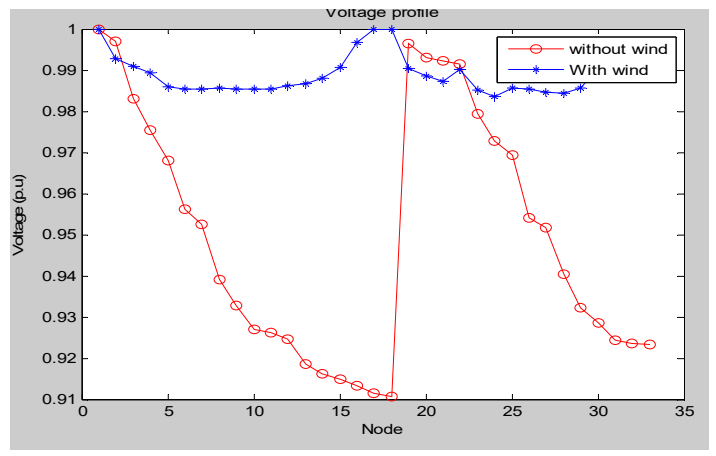

Figure 5. Bus Voltages Before and After Optimal DG Installation in the 33-Bus System

After insertion of the wind, it is noted that there is an improvement in all the voltages and an active loss reduction of the $33.355 \%$ as shown in the following table 1 .

Table 1. Power loss reduction.

\begin{tabular}{lll}
\hline & Without wind & With wind \\
\hline Power loss (KW) & 208.4592 & 138.9275 \\
Power loss reduction & - & $33.355 \%$ \\
Minimum voltage & 0.91075 & \\
\hline
\end{tabular}

The comparison for the real power losses in the branches is shown in Figure 6 for the initial network (with out wind) and with wind (case 1 and case 2), respectively, The power losses in almost every branch in case 2 reduced, except at 18,19, 20,21,33, 34 and 35, where there was a small increase in losses.

Optimal placement of wind turbine in a radial distribution network using PSO method (Yahiaoui Merzoug) 


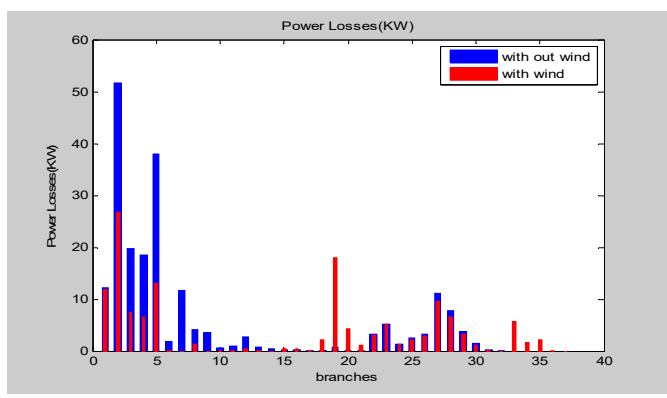

Figure 6. Real power losses in 33-bus system

\section{CONCLUSION}

The optimal insertion of wind turbines into the distribution network, the technique used to contribute to the management of distribution networks with the aim of minimizing total power losses by ensuring a good voltage profile, are carried out in the process of based on optimization by a meta heuristic method called pso algorithm. Many perspectives open up on the subject of the optimal insertion of decentralized production in the distribution network, in particular with regard to the types of DGs installed (photovoltaic, wind, etc.) and their maximum numbers to be installed, thus reconfiguring the distribution network taking into account other constraints such as transit limits and the assurance of continuity of service in the event of faults.

\section{REFERENCES}

[1] El-Fergany, Attia, "Optimal capacitor allocations using evolutionary algorithms," Generation, Transmission \& Distribution IET, vol. 7, no. 6, pp. 593-601, 2013.

[2] Seyed Mohsen Mousavi Khormandichali1, Mehrdad Ahmadi Kamarposhti, "Optimal placement of wind generation units in order to increase revenues and reduce the imposed costs in the distribution system considering uncertainty," International Journal of Electrical and Computer Engineering (IJECE), vol. 9, no. 6, pp. 4524-4539, Dec 2019.

[3] Katherine Cabana, John Candelo, Rafael Castillo, Emiro De-la-Hoz-Franco, "Voltage sensitivity analysis to determine the optimal integration of distributed generation in distribution systems," International Journal of Electrical and Computer Engineering (IJECE), vol. 9, no. 1, pp. 55-65, Feb 2019.

[4] Teng, Jen-Hao, "A direct approach for distribution system load flow solutions," Power Delivery, IEEE Transactions on, vol. 18, no. 3, pp. 882-887, 2003.

[5] H. Abdellatif, Z. Khaled, "Efficient load flow method for radial distribution feeders," Journal of Applied Science, vol. 13, pp. 741-8, 2006.

[6] Kittaya Somsai, "Controller design of UPQC for enhancing power quality in distribution system," International Journal of Power Electronics and Drive System (IJPEDS), vol. 9, no. 4, pp. 1591-1606, Dec 2018.

[7] Y. Xia, et al, "Wind turbine power coefficient analysis of a new maximum power point tracking technique," IEEE Transactions on Industrial Electronics, vol. 60, no. 3, pp. 1122-1132, Mar. 2013.

[8] Divya KC, Rao PSN., "Models for wind turbine generating systems and their application in load flow studies," Electri Power Syst Res, vol. 76, pp. 844-56, 2006.

[9] Sureshkumar Sudabattula, Kowsalya M, "Optimal allocation of wind based distributed generators in distribution system using Cuckoo Search Algorithm," 2nd International Conférence on Intelligent Computing, Communication \& Convergence (ICCC-2016), pp. 298-304, 2016.

[10] Ghofrani M., "A Framework for Optimal Placement of Energy Storage Units within a Power System with High Wind Penetration," IEEE TRANSACTIONS ON SUSTAINABLE ENERGY, vol. 4, no. 2, Apr 2013

[11] Bakhtvar M., "Optimal Allocation of Wind Generation Subject to Voltage Stability Constraints," IEEE PES Innovative Smart Grid Technologies, vol. 4, 2014.

[12] Satish Kansal, et al, "Optimal placement of distributed generation in distribution networks," International Journal of Engineering, Science and Technology, vol. 3, no. 3, pp. 47-55, 2011.

[13] Acharya N., Mahat P., Mithulananthan N., "An analytical approach for DG allocation in primary distribution network," Electric Power \& Energy Systems, vol.28, no.10, pp.669-678, Dec 2006.

[14] Ackermann T., Andersson G., and Solder L., "Distributed generation: a definition," Electric Power system Research, vol.57, no.3, pp. 195-204, Ap 2001.

[15] X. Wang, Y. Wang, H. Zeng, H. Zhou, "Particle swarm optimization with escape velocity," Int. Conf. on Computational Intelligent and Security, vol. 1, pp. 457-460, 2006.

[16] S. He, Q. H. Wu, J. Y. Wen, J. R. Saunders, R. C. Paton, "A particle swarm optimizer with passive congregation", Journal of Biosystems, vol. 78, pp. 135-147, 2004.

Int J Pow Elec \& Dri Syst, Vol. 11, No. 2, June 2020 : 1074 - 1081 
[17] Kennedy J., Eberhart R., "Particle Swarm Optimizer," IEEE International Conference on Neural Networks , Perth(Australia),IEEE Service Centre Piscataway, NJ, IV, pp. 1942-1948, 1995.

[18] Chiou, Ji-Pyng, et al, "Variable scaling hybrid differential evolution for solving network reconfiguration of distribution systems", IEEE Transactions on Power Systems, vol. 20, no. 2, pp. 668- 674, 2005

[19] A. Wazir and N. Arbab, "Analysis and optimization of IEEE 33 bus radial distributed system using optimization algorithm," Journal of Emerging Trends in Applied Engineering, vol. 1, no. 2, pp. 17-21, 2016.

[20] U. Sultana, A.B. Khairuddin, M.M. Aman, A.S. Mokhtar, N. Zareen, "A review of optimum DG placement based on minimization of power losses and voltage stability enhancement of distribution system," Renewable and Sustainable Energy Reviews, no. 63, pp. 363-378, 2016.

[21] A.M. El-Zonkoly., "Optimal placement of multi-distributed generation units including different load models using particle swarm optimization," Swarm and Evolutionary Computation, vol. 1, pp. 50-59, 2011.

[22] Khoa T.Q.D., Binh P.T.T., Tran H.B., "Optimizing location and sizing of distributed generation in distribution systems," Proceedings of IEEE PES Power Systems Conference and Exposition-PSCE 2006, pp. 725-732, 2006.

[23] University of Washington, "Power Systems Test Case Archive," Available online: https://www.ee.washington. edu/research/pstca/ (accessed on 12 June 2017).

[24] Kashem, M.A. Ganapathy, V. Jasmon, G.B. and Buhari, M.I., "A novel method for loss minimization in distribution networks," In Proceedings of International Conference on Electric Utility Deregulation and Restructuring and Power Technologies, pp. 251-255, 2000.

[25] http://www.synergyenviron.com/tools/wind_data.asp

\section{BIOGRAPHIES OF AUTHORS}

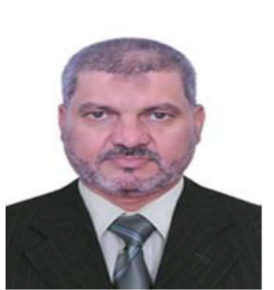

Yahiaoui Merzoug is born in Saida (Algeria) in 1966. He obtained a diploma of engineer in Electrotechnics in 1992. He received his master Department of Electrical Engineering at the ENSET, in Oran, Algeria. He received "Doctorat Es-Science" in Electrical Control from the University of Sciences and Technology of Oran (Algeria) in 2014. He is an associate professor at university of Saida. His fields of interest include: FACTS power flow in radial distribution system and Renewable Energies. I am a member in electro technical engineering Laboratory (L.G.E)).

Post address:Yahiaoui Merzoug , lecturer, University of Saida, BP 138 En-Nasr, (20000 Saida) , ALGERIA

Email: myahiaoui2001@yahoo.fr

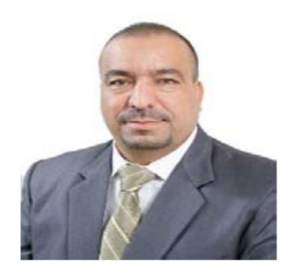

Bouanane Abdelkrim is born in SAIDA, Algeria in 1970 I obtained a diploma of engineer in Electrotechnics in 1995.I received my Master in 2006 at the ENSET Oran and PHD at the ENPO oran in 2013. I am a teatcher in the Department of Electrical Engineering, Faculty of Technology at the Dr. Moulay Taher University of SAIDA. My research interests include intelligent control of power system and FACTS, Electrical Machines and Renewable Energies.I am a member in electrotechnical engineering Laboratory (L.G.E))

Email: bouananeabd@yahoo.fr

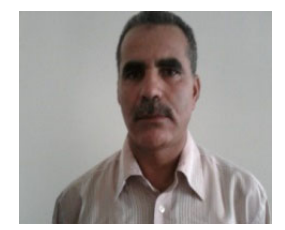

Boumediene Larbi is born in Saida (Algeria) in 1964. He obtained a diploma of engineer in Electrotechnics in 1990. He received his master Department of Electrical Engineering at the ENSET, in Oran, Algeria. He received "Doctorat Es-Science" in Electrical Control from the University of Sciences and Technology of Oran (Algeria) in 2010. He is an associate professor at university of Saida. His fields of interest include: harmonic power flow in distribution system, quality of energy. I am director of electro technical engineering Laboratory (L.G.E)). Post address: Larbi Boumediene, lecturer, University of Saida, BP 138 En-Nasr, (20000 Saida) , ALGERIA

Email: lboumediene2005@yahoo.fr

Optimal placement of wind turbine in a radial distribution network using PSO method (Yahiaoui Merzoug) 